\title{
Vorwort zum II. Band
}

1948 konnte ich den I. Band der "Europäischen Drogen" vorlegen, in dem in 90 Abschnitten (A-H) Drogen beschrieben werden, deren Hauptherkunftsgebiete in den europäischen Ländern liegen.

Für die anerkennenden Worte maßgebender Fachleute des Inund Auslandes und die wertvollen Hinweise, die mir übermittelt wurden, möchte ich an dieser Stelle meinen aufrichtigen Dank aussprechen.

Nach der Uberwindung einer Reihe technischer Schwierigkeiten konnte nunmehr auch der II. Band fertiggestellt werden, der in weiteren 114 Abschnitten (I-Z) Beschreibungen europäischer Drogen bringt, mit Hinweisen auf die pflanzliche Abstammung, die Standorte, den Anbau, die wichtigsten Handelsbezeichnungen in lateinischer, deutscher, englischer und französischer Sprache, die wesentlichsten Herkunftsgebiete, die Ernte und Beschreibung der Droge, die Bestandteile und die Anwendung. Die Abschnitte wurden ergänzt durch Angaben über Handels- und Verordnungsformen, Abarten, Verwechslungen, Verfälschungen und Bemerkungen über die Geschichte der Droge.

Der II. Band konnte mit 148 Originalzeichnungen illustriert werden.

Den Dank für die selbstlose und bereitwillige Mitarbeit der Wissenschaftler und Fachleute, die sich zur Verfügung stellten, und die Unterstützung des Verlages Cram, de Gruyter \& Co., möchte ich hier noch einmal zum Ausdruds bringen und hoffe, daß auch der II. Band eine freundliche Aufnahme finden wird. 